\title{
Cross-cultural adaptation of the CDC Worksite Health ScoreCard questionnaire into Portuguese
}

\author{
Patrícia Coelho de Soárez ${ }^{1 *}$, Rozana Mesquita Ciconelli², Thiago Pavin³, Alberto José Nituma Ogata ${ }^{4}$, Kátia Audi Curci ${ }^{3}$, \\ Martha Regina de Oliveira ${ }^{3}$ \\ ${ }^{1}$ PhD - Professor at the Department of Preventive Medicine, Faculdade de Medicina, Universidade de São Paulo (FMUSP), São Paulo, SP, Brazil \\ ${ }^{2} \mathrm{PhD}$ - MD, Escola Paulista de Medicina da Universidade Federal de São Paulo (Unifesp), São Paulo, SP, Brazil \\ ${ }^{3}$ MSc - Researcher at the Laboratório de Inovaçōes Assistenciais em Promoção da Saúde e Prevenção de Riscos e Doenças na Saúde Suplementar, Agência Nacional de Saúde Suplementar (ANS), São Paulo, SP, Brazi \\ ${ }^{4} \mathrm{MSc}$ - Coordinator at the Laboratório de Inovações Assistenciais em Promoção da Saúde e Prevenção de Riscos e Doenças na Saúde Suplementar, ANS, São Paulo, SP, Brazil
}

\footnotetext{
Study conducted at Departamento de Medicina Preventiva, Faculdade de Medicina da Universidade de São Paulo (FMUSP), São Paulo, SP, Brazil

Article received: 9/29/2014 Accepted for publication: 10/7/2014

*Correspondence: Address: Av. Dr. Arnaldo, 55, $2^{\circ}$ anda sala 2228 São Paulo, SP - Brazi Postal code: 01246-903 patricia.soarez@usp.br

http://dx.doi.org/10.1590/1806-9282.62.03.236

Financial support: Pan American Health Organization (PAHO)
}

\section{SUMmARY}

Objective: Despite the progress in the implementation of health promotion programs in the workplace, there are no questionnaires in Brazil to assess the scope of health promotion interventions adopted and their scientific basis. This study aimed to translate into Brazilian Portuguese and culturally adapt the CDC Worksite Health ScoreCard (HSC) questionnaire.

Method: The HSC has 100 questions grouped into twelve domains. The steps are as follows: translation, reconciliation, back-translation, review by expert panel, pretesting, and final revision. The convenience sample included 27 individuals from health insurance providers and companies of various sizes, types and industries in São Paulo. Data were analyzed using descriptive statistics.

Results: The average age of the sample was 38 years, most of the subjects were female (21 of 27), and were responsible for programs to promote health in these workplaces. Most questions were above the minimum value of understanding set at $90 \%$. The participants found the questionnaire very useful to determine the extent of existing health promotion programs and to pinpoint areas that could be developed.

Conclusion: The Brazilian Portuguese version of the HSC questionnaire may be a valid measure and useful to assess the degree of implementation of health promotion interventions based on evidence in local health organizations.

Keywords: health promotion, occupational health, occupational health services, surveillance in occupational health.

\section{INTRODUCTION}

Chronic non-communicable diseases (CNCD) are the leading cause of mortality and burden of disease in most countries in the world. ${ }^{1}$ In the United States of America, estimates of the total cost of cardiovascular diseases, including heart disease and strokes, totaled US\$ 444 billion in 2010. ${ }^{2}$ For medium/high income countries such as Brazil, the estimated annual cost is $4 \%$ of the GDP, i.e. approximately US\$139 per capita per year. ${ }^{3}$ Estimates for Brazil suggest that the loss of productivity at work and decreased family income resulting from merely three CNCD (diabetes, heart disease and stroke) will lead to a loss in the Brazilian economy of US $\$ 4.18$ billion between 2006 and $2015 .^{4}$
Faced with the exponential growth of health costs, many employers are implementing evidence-based health promotion programs, including individual risk reduction programs, connected to environmental support for healthy behaviors, coordinated and integrated into other activities related to wellbeing, which has been shown to be the most efficient strategy to reduce the risk of developing chronic diseases. ${ }^{5-7}$

Several studies have concluded that health promotion programs in the workplace can improve employee health and reduce the health expenditure of employers. ${ }^{8-10}$ In North America, $76 \%$ of companies have some kind of health promotion program. In Latin America, this figure reaches $43 \%{ }^{11}$ 
In Brazil, $59 \%$ of the health promotion programs have existed for up to five years, and only $17 \%$ have fully implemented their strategies. Only $31 \%$ of companies measure specific results of ongoing programs, others do not do so due to unfamiliarity with methodologies $(58 \%)$, lack of funding (47\%) or lack of interests among their leaders $(18 \%)$. Fifty-three percent of these companies expect a reduction in costs related to health insurance as a result of the health promotion programs. ${ }^{11}$

Although advancements have been detected in the implementation of health promotion programs in the workplace, we don't have a questionnaire available in the area to evaluate the scope of the health promotion interventions adopted and the extent to which these interventions are based on scientific evidence.

Through the Laboratory of Care Innovations in Health Promotion and Prevention of Risks and Diseases in Supplementary Health, the National Regulatory Agency for Private Health Insurance and Plans (ANS) has identified a questionnaire specifically designed for this evaluation, the Center for Disease Control and Prevention (CDC) Worksite Health ScoreCard (HSC). The choice of this questionnaire was based on the demonstration of its psychometric properties, as well as its use in organizations of different sizes in the United States of America. ${ }^{12}$

The HSC is a questionnaire designed to help employers assess how their health promotion programs have implemented evidence-based health promotion interventions in their workplaces, identifying gaps and prioritizing high impact interventions to prevent heart disease, stroke and related chronic diseases. Their psychometric properties, validity and reliability, have been previously evaluated in a validation study that involved a sample of $93 \mathrm{em}-$ ployers from different locations in the United States. ${ }^{12,13}$

This self-assessment questionnaire includes questions about evidence-based key interventions of best practices, which have been recommended to be included in programs for the prevention of heart disease and strokes in workplaces. It has 100 questions (dichotomous "YES" or "NO"), which ask employers if they have a specific intervention or program in their workplaces. The questions are grouped into twelve domains (Chart 1).

In each question, the values can range from 1 to 3 points (where $1=$ good, $2=$ very good, $3=$ excellent). This value reflects the potential impact that the strategy has on the desired results or health behavior and the weighting of the scientific evidence that supports this impact. The total score and the specific topics are added based on the values of the weighting assigned to each question that
CHART 1 CDC Worksite Health ScoreCard (HSC).

\begin{tabular}{ll} 
Domains & $\begin{array}{l}\text { Number of } \\
\text { questions }\end{array}$ \\
\hline Organizational support & 18 \\
\hline Smoking control & 10 \\
\hline Nutrition & 13 \\
\hline Physical activity & 9 \\
\hline Weight control & 5 \\
\hline Stress management & 6 \\
\hline Depression & 7 \\
\hline High blood pressure & 7 \\
\hline High cholesterol & 6 \\
\hline Diabetes & 6 \\
\hline Signs and symptoms of stroke and heart attack & 4 \\
\hline Response to emergency in case of stroke and heart attack & 9
\end{tabular}

received the reply "YES". The "NO" responses receive a score of zero. The total score may range from 0 to 215 .

The CDC Worksite Health ScoreCard (HSC) was designed in English and, therefore, intended for use in English-speaking populations. To use this questionnaire in other languages it is necessary to follow an appropriate methodology for translation, cultural adaptation and validation before its application.

The process of translation and cultural adaptation should follow internationally accepted procedures ${ }^{14-16}$ to ensure that the new version of the translated and adapted questionnaire is actually appropriate to the culture and language of the location where it will be applied, and obtain results that can be compared to those of other international studies. ${ }^{17}$

The aim of this study was to translate and culturally adapt the CDC Worksite Health ScoreCard (HSC) questionnaire to Brazilian Portuguese.

\section{Method}

This research is a study of the translation and cultural adaptation of a questionnaire, conducted by researchers of the Department of Preventive Medicine at the Faculdade de Medicina, Universidade de São Paulo (FMUSP) and the Department of Medicine at the Faculdade de Medicina, Universidade Federal de São Paulo (Unifesp) in collaboration with the Pan American Health Organization (PAHO) - Brazil/World Health Organization (WHO), and the National Regulatory Agency for Private Health Insurance and Plans (ANS) - Laboratory of Care Innovations in Health Promotion and Prevention of Risks and Diseases in Supplementary Health. 
The translation and cultural adaptation of the instrument followed the guidelines, ${ }^{14-16}$ which recommend translation, reconciliation of translations, back-translation, revision by the Expert Committee, evaluation of cultural adaptation (pretesting) and final revision (Figure 1)

Before the start of this process, the authors of the original instrument were contacted by the ANS and sent an authorization request in writing for conducting this study.

Through collaboration with the ANS and the Laboratory of Care Innovations in Health Promotion and Prevention of Risks and Diseases in Supplementary Health, 40 individuals working in the health promotion programs of health insurance operators or companies were invited to participate.

The data were collected in person at two different times: Pretesting 1 at the ANS head office in São Paulo and Pretesting 2 at the head office of the Brazilian Quality of Life Association (ABQV). The questionnaires were self-administered.

\section{RESULTS}

The convenience sample included 27 individuals from health insurance providers and companies of various sizes, types and industries in São Paulo. The average age of the sample was 38 years, and most of the individuals who

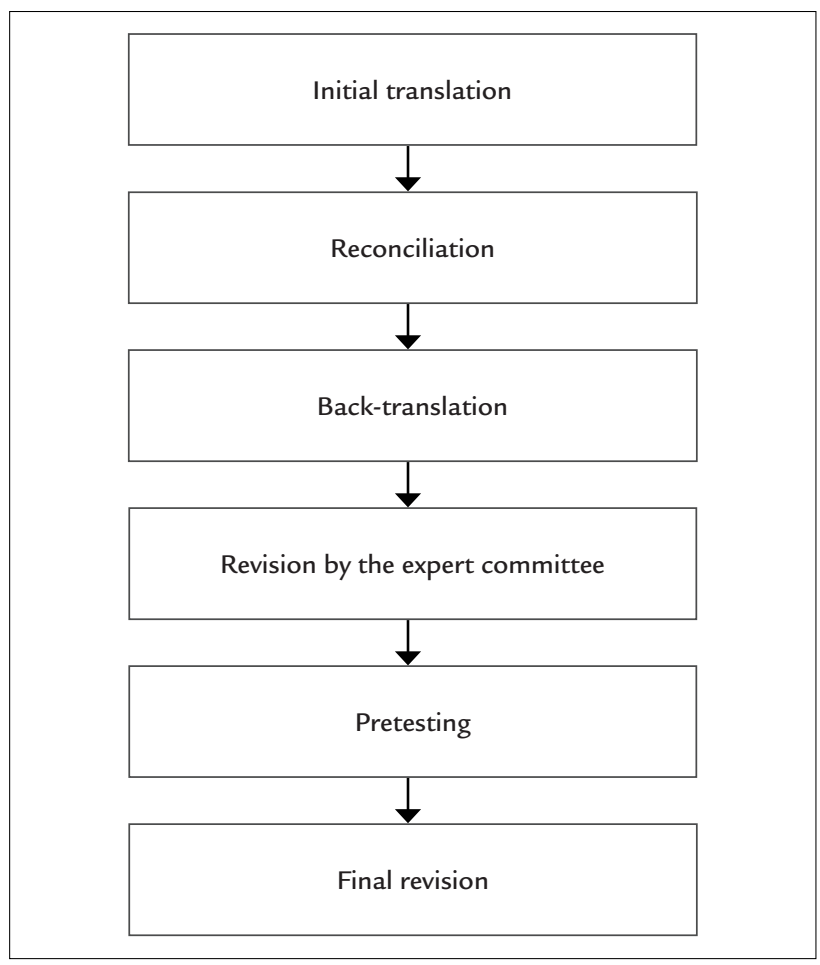

FIGURE 1 Stages in the translation and cultural adaptation process. answered the questionnaire were female (21 out of 27 ) and responsible for health promotion programs at these workplaces. Table 1 provides a summarized description of the sample studied.

TABLE 1 Characteristics of the participants. São Paulo, SP, Brazil, 2013.

\begin{tabular}{|c|c|}
\hline$(n=27)$ & $\%$ \\
\hline Average age (years) & 38 \\
\hline \multicolumn{2}{|l|}{ Gender } \\
\hline Male & 22.2 \\
\hline Female & 77.8 \\
\hline \multicolumn{2}{|l|}{ Formal education } \\
\hline Undergraduate level & 32.0 \\
\hline Graduate level & 68.0 \\
\hline \multicolumn{2}{|l|}{ Respondent's position } \\
\hline Wellness and quality of life programs team & 7.7 \\
\hline Human resources team & 3.8 \\
\hline Management & 34.6 \\
\hline Medical area team & 53.8 \\
\hline \multicolumn{2}{|l|}{ Size of the organization } \\
\hline Very small & 7.4 \\
\hline Small & 25.9 \\
\hline Mid-sized & 22.2 \\
\hline Large & 44.4 \\
\hline \multicolumn{2}{|l|}{ Type of organization } \\
\hline For profit & 55.6 \\
\hline Non profit & 44.4 \\
\hline \multicolumn{2}{|l|}{ Economic activity* } \\
\hline Extractive industry & 3.7 \\
\hline International organizations and other institutions & 3.7 \\
\hline Transport, storage and courier & 3.7 \\
\hline Information and communication & 7.4 \\
\hline Public administration, defense and social security & 7.4 \\
\hline Manufacturing industries & 14.8 \\
\hline Financial activities, insurance and related services & 59.3 \\
\hline
\end{tabular}

For this study, the following definitions for organizational size according to the CDC were used: Very small (10 to 99 employees); small (100 to 249 ); mid-sized (250 to 749 ); and large (+750) *Defined according to the Brazilian National Classification of Economic Activities (CNAE).

\section{Translation}

Initial translation

The items in the original version of the HSC were translated initially by two independent professionals with previous experience in translation of patient reported outcomes (PRO) measurements, Brazilian nationals, resident in Brazil, with extensive knowledge of the English language and who were aware of the research goals. The importance of a conceptual translation rather than a strict- 
ly literary translation was emphasized. We therefore obtained versions no. 1 and no. 2 in Portuguese.

\section{Reconciliation}

The researcher responsible for conducting the entire process, who prepared one of the initial versions of the translations (no. 1 in Portuguese), carried out the reconciliation between versions no. 1 and no. 2 in Portuguese, producing version no. 3 in Portuguese. The decisions made during the reconciliation process were reviewed by the Expert Committee, ensuring consistency and harmonization with the translated versions.

Some questions were modified to ensure experiential equivalence. For example, in the personal information section question $2 \mathrm{e}$ related to color/race, the categories available in the original instrument (Non-Hispanic White, Non-Hispanic Black/African American, Hispanic/Latino, Asian/Asian American, American Indian/Alaska Native, Native Hawaiian/Pacific Islander, Others) were replaced by the categories used by the Brazilian Census Bureau, IBGE (white, black, yellow, brown, native, others).

In question 4 , concerning the type of economic activity of the organization, the categories were replaced by the Brazilian National Classification of Economic Activities (CNAE).

The following phrase appears in the explanation of question 22 in the Tobacco Control topic: "refer tobacco users to 1-800-QUIT-NOW or smokefree.gov". These terms were replaced by the "Dial Health" Quit Smoking service: 0800611997 or the National Program for Tobacco Control (http://www1.inca.gov.br/tabagismo/).

In question 24, in the phrase "nicotine replacement products approved by the FDA," the term FDA was replaced by Anvisa.

In the Nutrition topic, question 32, the phrase consult the "Dietary Guidelines for Americans, 2010, or GSA/HHS Health and Sustainability Guidelines for Federal Concessions and Vending Operations" was replaced by the Dietary Guide for the Brazilian Population or the Guidelines for Federal Operations of Points of Sale.

In question 44 , the basketball court was replaced by a sports court. This is because the practice of basketball is not as common in Brazil as in the United States.

\section{Back-translation}

The initial versions of the translations (no. 1 and no. 2 in Portuguese) were translated into English by two independent English teachers, American nationals, who did not participate in the previous stage and were unaware of both the goals and concepts presented in the question- naire. For practical reasons we recommended more literals back-translations in order to facilitate comparisons with the original instrument. Only in more subjective items more conceptual back-translations were indicated.

\section{Revision by the Expert Committee}

Next, a comparison was made of the original instrument with the 3 versions produced in Portuguese and the 2 versions in English. The expert panel composed of six health professionals (three physicians, two public health professionals with experience in translation of questionnaires, and a psychologist) documented and analyzed the discrepancies found. Some verb tenses and sentences in Portuguese were rewritten until a consensus was reached. Version no. 4 in Portuguese was thereby created.

\section{Cultural adaptation}

\section{Evaluation of cultural adaptation (Pretesting 1)}

This step is designed to assess the degree of understanding of the questions, and to identify and explain problems related to the formulation or content of the questions.

The participants received an explanation of the objectives and methodology of the study. We asked for permission to use their responses, assuring that the data would be always displayed in aggregated form and that the confidentiality of the individuals would be maintained.

Version no. 4 of the questionnaire, in Portuguese, was answered by a group of 14 individuals responsible for health promotion programs in health operators. A paper copy of version no. 4 was delivered, as well as a paper form, which asked if each of the questions in the questionnaire had been understood. If not, the participant was asked to write the word or phrase that had not been understood and how they would rewrite this question to make it more understandable.

The participants took approximately 60 minutes to answer the questionnaire and fill out the form. After completion, one of the researchers asked the participants if they had generally understood the questions in the questionnaire, if they were able to answer the questions easily, and if these questions could be applied to the health promotion programs at their workplaces. At the end, they were asked whether they found the HSC a useful and relevant questionnaire that could be implemented in their workplace.

One of the researchers discussed all of the queries, comments and suggestions from the participants, and another researcher noted the emerging points in detail using a specific form.

Before the start of the study, a minimum level of understanding of $90 \%$ was determined, that is, each ques- 
tion should be understood by at least $90 \%$ of individuals. Questions with an understanding below $90 \%$ would be automatically identified and subject to revision.

In Pretesting 1, 8 of the 100 questions were below the minimum level of understanding of $90 \%$, and were subjected to the revision process.

The discussion held with individuals after filling out the questionnaire provided very useful data for explaining why these 8 questions had not been understood.

The first major difficulty faced by individuals representing the health insurance operators was to understand which health promotion program they were evaluating: Health promotion programs from the health insurance plans offered to beneficiaries in their portfolios or health promotion programs available to their own employees.

Some individuals had difficulty in understanding specific words, for example, "self-management programs", and found that some activities did not make sense in the Brazilian context, such as "feira livre" (used for the translation of "farmers' Market"), and "dial to stop smoking". The explanations of certain questions were considered confusing and hindered answering.

The majority of the individuals considered the questionnaire very useful to determine the scope of the existing health promotion programs and to point out areas that could be developed and/or improved in the current programs.

\section{Revision by the Expert Committee}

The questions identified as having an understanding below $90 \%$ were discussed by the expert committee.

The emerging points detailed in the specific form were transformed into the summary file, where the questions that were not understood were quantified and specified. This summary was fundamental for emphasizing the words not understood, misinterpretations, or instructions that were not sufficiently clear. The expert committee evaluated these words and replaced them with others with the same idea but more easily understood, including suggestions from the individuals themselves, seeking to change the structure and evaluation properties of such questions. Some verb tenses and sentences in Portuguese were rewritten until a consensus was reached. Versions no. 5 in Portuguese was thereby created.

\section{Evaluation of cultural adaptation (Pretesting 2)}

This step is designed to evaluate the degree of understanding of the questions again, and to identify if the problems related to the formulation or content of the questions identified in the previous version remained in the current one.
In the same manner as Pretesting 1, the participants received an explanation of the objectives and methodology of the study. We asked for permission to use their responses, assuring that the data would be always displayed in aggregated form and that the confidentiality of the individuals would be maintained.

Version no. 5 was applied to another group of 13 individuals, responsible for the health promotion programs of their organizations. A paper copy of version no. 5 and the form were delivered, as described earlier.

The participants took approximately 60 minutes to answer the questionnaire and fill out the form. Upon completion, the questions asked in Pretesting 1 were repeated, and the queries, comments and suggestions of the participants were discussed and noted in a specific form by one of the researchers.

In Pretesting 2, only 6 of the 100 questions did not present adequate understanding. As expected, in this group made up of managers or administrators of health promotion programs at companies, the general understanding was better than that of the previous group, composed of managers or administrators of health insurance operators, given that the HSC was developed for application in companies.

In this second application the individuals had difficulty understanding some specific expressions, for example: how many classes would "a series of classes" exactly mean? 3,6 or 10 classes? They indicated the almost nonexistence of vending machines in their companies and suggested including the dining areas next to cafeterias and snack bars in these questions. Another difficulty encountered was related to the subsidies mentioned in several questions. Some argued whether these issues were applicable to our area, because subsidies are not a common form of benefits offered to employees locally.

In the same way as in the pretesting 1 , individuals considered the questionnaire very useful for evaluating the existing health promotion programs and suggesting areas that have not yet been developed in current programs.

The questions that presented problems of understanding were rewritten. The researcher responsible and a reviser checked the final translation and corrected spelling, grammatical, typographical or other remaining typing mistakes. Version no. 6 in Portuguese was thereby created.

\section{Revision by the Expert Committee}

After Pretesting 2, another summary file was created, where the questions not understood were quantified and specified. The expert committee reviewed this detailed summary of the words and phrases not understood and the 
suggestions made in the forms. During this phase, the experts again changed certain questions that still had problems being understood.

\section{Final revision}

Next, the researcher responsible and a reviser checked the final translation and corrected spelling, grammatical, typographical or other remaining typing mistakes. Version no. 6 in Portuguese was thereby created. The Brazilian version of the CDC Health ScoreCard (HSC) is available online on the website of the National Regulatory Agency for Private Health Insurance and Plans: http://www. ans.gov.br/.

\section{Discussion}

The development of the Brazilian version of the CDC Health ScoreCard (HSC) is based on the importance of terms available in our language, as a questionnaire that evaluates how evidence-based health promotion strategies are implemented in the workplace of Brazilian organizations.

As such, we strictly followed the internationally accepted translation and cultural adaptation processes. ${ }^{14-16}$

In the initial translation, according to the methodological guidelines, the researcher responsible for the entire translation and cultural adaptation process produced one of the translated versions (no. 1 in Portuguese). The comparison of the two versions developed (no. 1 and no. 2 in Portuguese) allowed us to detect errors and differences in the interpretation of ambiguous items.

The researcher responsible also conducted the reconciliation between versions no. 1 and no. 2 in Portuguese, producing version no. 3 in Portuguese. However, all of the decisions made during the reconciliation process were detailed, documented and approved by the expert committee.

In Pretesting 1 and 2, difficulties similar to those reported in the validation of the instrument in the United States were reported. For example, individuals have had difficulty understanding the meaning of "self-management programs", and also found the examples and explanations of some questions too lengthy. ${ }^{12}$

In the expert committee review, the experiential equivalence of questions relating to the use of vending machines was discussed, as some individuals had questioned the validity of such questions, due to the small number of these machines available in Brazilian companies.

Another issue discussed by the Committee was the experiential equivalence of questions related to subsidies. Unlike the American context, companies in Brazil do not commonly subsidize the purchase of healthy foods and beverages, risk factor evaluations, physical activity, counseling programs or self-management for weight control, screening for depression, high blood pressure, high cholesterol, diabetes, smoking cessation, etc.

Our study has certain limitations, one of which is the representativeness of the convenience sample, which only included respondents from the State of São Paulo, Brazil. Despite the small number of respondents, most of them considered the questionnaire very useful to assess existing health promotion programs and to indicate areas that have not yet been developed in current programs.

\section{Conclusion}

The final version of HSC in Brazilian Portuguese may be a valid and useful tool for measuring the degree of implementation of evidence-based health promotion interventions in Brazilian companies and health care organizations. In order to make the HSC widely available, future studies with larger samples that are representative of all Brazilian regions will be needed to assess the psychometric properties (validity and reliability) of this instrument in the Brazilian context.

\section{Resumo}

Adaptação cultural do questionário CDC Worksite Health ScoreCard para o português

Objetivo: apesar do avanço na implementação dos Programas de Promoção da Saúde nos locais de trabalho, não temos disponível no Brasil um questionário que avalie a abrangência das intervenções de promoção da saúde adotadas e seu embasamento científico. Este estudo teve o objetivo de traduzir para o português brasileiro e adaptar culturalmente o questionário CDC Worksite Health ScoreCard (HSC).

Método: o HSC possui 100 questões agrupadas em doze domínios. Foram seguidas as etapas: tradução, reconciliação, retro-tradução, revisão pelo painel de especialistas, pré-teste e revisão final. A amostra de conveniência incluiu 27 indivíduos de operadoras de planos de saúde e empresas de diversos tamanhos, tipos e indústrias do Estado de São Paulo. Os dados foram analisados por meio da estatística descritiva.

Resultados: a média de idade da amostra foi de 38 anos; a maioria dos indivíduos eram do sexo feminino $(21$ de 27) e eram os responsáveis pelos programas de promoção da saúde desses locais de trabalho. A maioria das questões ficou acima do nível mínimo de compreensão de $90 \%$. 
Os indivíduos consideraram o questionário muito útil para determinar a abrangência dos programas de promoção da saúde existentes e apontar áreas que poderiam ser desenvolvidas.

Conclusão: a versão em português brasileiro do questionário HSC poderá ser uma ferramenta válida e útil para medir o grau de implantação das intervenções de promoção da saúde baseadas em evidências em organizações de saúde locais.

Palavras-chave: promoção da saúde, saúde do trabalhador, serviços de saúde do trabalhador, vigilância em saúde do trabalhador.

\section{REFERENCES}

1. World Health Organization (WHO). Global status report on non communicable diseases 2010. Geneva: WHO, 2011.

2. Centers for Disease Control and Prevention. Chronic diseases: the power to prevent, the call to control: at a glance 2011. Atlanta: US Department of Health and Human Services, 2011.

3. Bloom D, Chisholm D, Jané-Llopis E. From burden to "Best Buys": reducing the economic impact of noncommunicable disease in low-and middleincome countries. World Economic Forum. Geneva, 2011. Available from: http://www.who.int/nmh/publications/best_buys_summary.pdf.

4. Abegunde DO, Mathers CD, Adam T, Ortegon M, Strong K. The burden and costs of chronic diseases in low-income and middle-income countries Lancet. 2007; 370(9603):1929-38.

5. Goetzel RZ, Shechter D, Ozminkowski RJ, Marmet PF, Tabrizi MJ, Roemer EC. Promising practices in employer health and productivity management efforts: findings from a benchmarking study. J Occup Environ Med. 2007; 49(2):111-30.
6. Soler RE, Leeks KD, Razi S, Hopkins DP, Griffith M, Aten A, et al. A systematic review of selected interventions for worksite health promotion. The assessment of health risks with feedback. Am J Prev Med. 2010; 38(2 Suppl):S237-62.

7. Heaney CA, Goetzel RZ. A review of health-related outcomes of multicomponent worksite health promotion programs. Am J Health Promot. 1997; 11(4):290-307.

8. Linnan L, Bowling M, Childress J, Lindsay G, Blakey C, Pronk S, et al. Results of the 2004 National Worksite Health Promotion Survey. Am J Public Health. 2008; 98(8):1503-9.

9. Chapman L. Meta-evaluation of worksite health promotion economic return studies. Art Health Promotion Newsletter. 2003; 6(6):1-10.

10. Baicker K, Cutler D, Song Z. Workplace wellness programs can generate savings. Health Aff (Millwood). 2010; 29(2):304-11.

11. Buck Consultants. Working well: a global survey of health promotion and workplace wellness strategies - Survey report. San Francisco, 2012.

12. Roemer EC, Kent KB, Samoly DK, Gaydos LM, Smith KJ, Agarwal A, et al Reliability and validity testing of the CDC Worksite Health ScoreCard: an assessment tool to help employers prevent heart disease, stroke, and related health conditions. J Occup Environ Med. 2013; 55(5):520-6.

13. Centers for Disease Control and Prevention. The CDC Worksite Health ScoreCard: an assessment tool for employers to prevent heart disease, stroke, and related conditions. Atlanta: US Department of Health and Human Services, 2012

14. Guillemin F, Bombardier C, Beaton D. Cross-cultural adaptation of health related quality of life measures: literature review and proposed guidelines. J Clin Epidemiol. 1993; 46(12):1417-32.

15. Beaton DE, Bombardier C, Guillemin F, Ferraz MB. Guidelines for the process of cross-cultural adaptation of self-report measures. Spine (Phila Pa 1976). 2000; 25(24):3186-91.

16. Wild D, Grove A, Martin M, Eremenco S, McElroy S, Verjee-Lorenz A, et al. Principles of Good Practice for the Translation and Cultural Adaptation Process for Patient-Reported Outcomes (PRO) Measures: report of the ISPOR Task Force for Translation and CultuZral Adaptation. Value Health. 2005; 8(2):94-104.

17. Herdman M, Fox-Rushby J, Badia X. 'Equivalence' and the translation and adaptation of health-related quality of life questionnaires. Qual Life Res 1997; 6(3):237-47 